\title{
A preparation for the experimental analysis of human cigarette smoking behavior
}

\author{
JACK E. HENNINGFIELD and ROLAND R. GRIFFITHS \\ Department of Psychiatry, Baltimore City Hospitals \\ Baltimore, Maryland 21224 \\ and \\ Department of Psychiatry, The Johns Hopkins University \\ School of Medicine, Baltimore, Maryland 21205
}

\begin{abstract}
A preparation for the experimental analysis of cigarette smoking is described in detail. The preparation permits the intensive study of cigarette smoking in individual subjects under controlled laboratory conditions. A variety of behavioral and physiological measures used include rate and pattern of puffing, duration of each puff, time spent smoking cigarettes, expired air carbon monoxide levels, cigarette butt weights, and subjective rating scales of various aspects of smoking. The preparation is reliable and permits relatively unobtrusive monitoring of smoking performance. Cigarette smoking occurs in orderly patterns, within subjects; it varies as a function of number of cigarettes provided and hours of smoking deprivation.
\end{abstract}

Despite the fact that cigarette smoking is the most wide-spread and persistent of all forms of substance abuse, there is surprisingly little known about its behavioral and pharmacological determinants. There is little consensus as to the variables controlling smoking (e.g., Horn, 1976; Jarvik, 1970; Russell, 1979; Schacter, 1979). It appears that a fundamental requirement of future cigarette smoking research is the development of an adequate experimental preparation.

This report provides a description of a technology and methodology for analyzing human cigarette smoking. Various aspects of this methodology evolved in the 1970s. Important contributors to the evolution include Frederiksen and Martin (1979), Gritz and Jarvik (1978), and Russell (1976). The experimental preparation described here permits unobtrusive monitoring of the rate and pattern of multiple elements of cigarette smoking behavior, including puffing and carbon monoxide (CO) intake. Experiment 1 involves the use of the preparation to characterize cigarette smoking performance under ad-lib smoking conditions and to assess the reliability of the preparation. Experiments 2 and 3 involve manipulation of the number of cigarettes available and the deprivation state, respectively, and provide additional

This research was supported by USPHS Grant DA 01935. We thank Penny Edwards and Cheryl Mercer for their assistance in conducting the experiments, John Yingling for developing the computer program, William Bixler for assistance in constructing the test rooms, technical assistance of the Department of Psychiatry and Behavioral Biology at The Johns Hopkins University School of Medicine for developing the puff monitoring system, and Frank Funderburk for assisting in statistical analysis of the data. In addition, we thank Ellen Gritz and Murray Jarvik for their helpful advice, particularly with regard to the construction of the thermistor-triggered puff monitoring system. Requests for reprints should be sent to Roland R. Griffiths, Department of Psychiatry, The Johns Hopkins University School of Medicine, Baltimore, Maryland 21205. information that bears on the validity of the preparation as a model for human cigarette smoking as it occurs in the nonlaboratory environment.

\section{EXPERIMENT 1: PATTERNS OF CIGARETTE SMOKING DURING EXPERIMENTAL SESSIONS}

The cigarette smoking preparation was first used to characterize temporal patterns of smoking under ad-lib smoking conditions. This simple first experiment permitted concurrent evaluation of the dependent variables and thus provided preliminary data relevant to validation of the preparation.

\section{Method}

Subjects. Nineteen heavy cigarette smokers participated (Table 1). Five of the volunteers (H.I., W.E., D.A., A.M., and M.C.) had histories of drug or alcohol dependence and resided on the inpatient behavioral pharmacology research unit at Baltimore City Hospital during these studies. The remaining 14 subjects were volunteers from the local community. All subjects were given routine physical examinations to assure fitness. Subjects were required to abstain from smoking for $30 \mathrm{~min}$ preceding experimental sessions and to abstain from use of other psychoactive drugs (including caffeinated beverages) for at least $12 \mathrm{~h}$ preceding sessions.

Apparatus. Two test rooms were equipped with devices to monitor and control cigarette smoking behavior (Figure 1). Each toom was well ventilated and measured $1.5 \times 4 \mathrm{~m}$ with 2.4-m ceilings.

A television, cushioned chair, and smoking console were present in each test chamber. A $60 \times 60 \mathrm{~cm}$ one-way window (mounted on the wall facing the subject) provided unobtrusive visual access to the subject. Figure 1 shows a smoking console readily accessible in each chamber and equipped with (1) an automobile-type cigarette lighter whose operation triggered a relay, (2) a slidelever-operated cigarette butt depository that prevented visual access to the cigarette remains and the operation of which closed a microswitch, (3) a stimulus light signaling session onset, and (4) a connection point for the cigarette holders. The cigarette holders were commercially available 
Table 1

Experiment 1: Subject Characteristics

\begin{tabular}{|c|c|c|c|c|c|}
\hline Subject & Sex & Age & $\begin{array}{c}\text { Years } \\
\text { Smoking }\end{array}$ & Brand & $\begin{array}{c}\text { Cigarettes } \\
\text { per Day }\end{array}$ \\
\hline A.M. & M & 46 & 34 & Marlboro & 20 \\
\hline R.O. & $\mathrm{F}$ & 21 & 6 & $L \& M$ & 20 \\
\hline O.W. & $\mathbf{M}$ & 21 & 8 & Newport & 30 \\
\hline H.E. & $\mathrm{F}$ & 19 & 3 & Winston & 30 \\
\hline G.A. & $\mathrm{F}$ & 30 & 20 & Pall Mall & 35 \\
\hline H.I. & $\mathbf{M}$ & 40 & 25 & Chesterfield & 40 \\
\hline Y.A. & $\mathrm{F}$ & 20 & 5 & Kool & 50 \\
\hline M.O. & $\mathrm{F}$ & 28 & 12 & Salem & 30 \\
\hline H.A. & $\mathrm{F}$ & 21 & 4 & Marlboro & 20 \\
\hline T.A. & $\mathrm{F}$ & 18 & 5 & Marlboro & 30 \\
\hline D.A. & $\mathrm{M}$ & 50 & 39 & Chesterfield & 40 \\
\hline A.Y. & $\mathrm{F}$ & 41 & 27 & Marlboro & 40 \\
\hline M.C. & $\mathrm{M}$ & 42 & 32 & Kool & 40 \\
\hline S.T. & $\mathrm{F}$ & 36 & 18 & Marlboro & 30 \\
\hline P.I. & $\mathrm{M}$ & 37 & 23 & Pall Mall & 30 \\
\hline L.A. & $\mathbf{M}$ & 18 & 5 & Winston & 50 \\
\hline W.E. & $\mathbf{M}$ & 39 & 28 & Winston & 40 \\
\hline W.A. & $\mathrm{M}$ & 30 & 16 & Carlton & 30 \\
\hline M.I. & $\mathrm{M}$ & 31 & 17 & Kool & 35 \\
\hline
\end{tabular}

plastic holders (Aquafilter Corporation, Opa Locha, Florida) that had been cut to $35-\mathrm{mm}$ length (from the tip of the holder) with the filtration material removed to provide a simple tubular holder. All subjects tested indicated that the holder did little to change the draw or other meaningful characteristics of cigarette smoking. Holders were washed in $95 \%$ ethanol before each test session and were replaced as necessary.

A different type of puff monitor was used in each test chamber. In Chamber 1, a 2-m length of black PVC tubing (.8-mm o.d.) was connected to the cigarette holder by a $30-\mathrm{mm}$

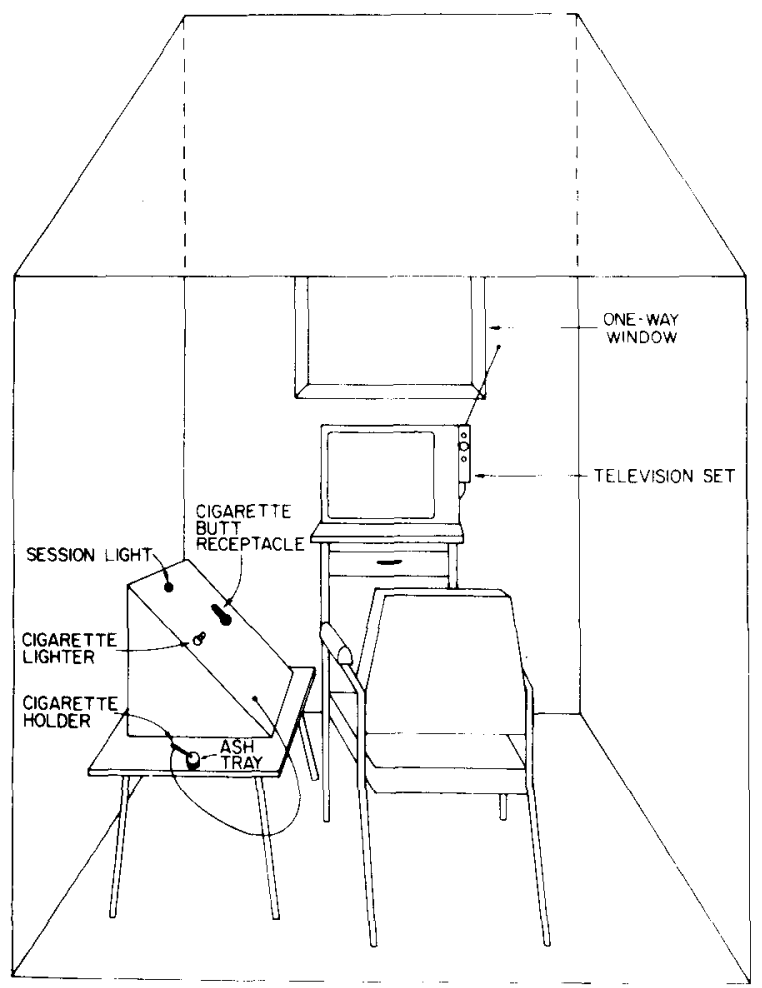

Figure 1. Diagram of test room and cigarette smoking console. 18-gauge needle inserted perpendicularly at the midway point of the cigarette holder. The other end of the tubing was connected to a pressure transducer (P-23-DE, Statham Company, Oxnard, California) that operated a relay following a decrease in pressure produced by puffing on a cigarette. In Chamber 2 , a 2-m length of dual-lead 21-gauge wire was affixed at the midway point of the cigarette holder using an epoxy resin; it was connected to a pinhead-sized thermistor epoxied inside the holder. The thermistor triggered a relay when temperature changes produced by puffing on a cigarette occurred. These puff monitors, along with other previously described components of the cigarette smoking consoles, were interfaced to a DEC PDP-8/e computer. A SKED-based software system (State Systems, Inc., Kalamazoo, Michigan) was adapted to the computer and to the requirements of the research to record, control, and process experimental events.

Procedure. Each subject was monitored from 5 to 20 experimental sessions (Table 2 ) (mean $=9.5$ sessions). Sessions were $3 \mathrm{~h}$ for 12 subjects, $2 \mathrm{~h}$ for 1 subject, and $1.5 \mathrm{~h}$ for 6 subjects. Each subject was tested at the same time of the day, 5 days per week. Subjects were required to remain in the test room except for necessary trips to the lavatory. Each subject was provided with a daily newspaper and access to the television set but was not allowed to engage in any writing or craft activities or to eat food. Subjects were provided with one fresh package of their usual brand of cigarettes before each session (except as described in Experiment 3). They were told that they could smoke as much or as little as they chose but to use the cigarette holder, lighter, and butt depository as instructed.

Subjects were arbitrarily assigned to one of the two puff monitoring systems: Twelve subjects (A.M., H.E., Y.A., M.O., H.A., D.A., M.C., S.T., P.I., L.A., W.E., M.I.) were tested using the thermistor puff monitoring system. Three subjects (M.C., S.T., M.I.) were also tested using the pressure transducer puff monitoring system. The remaining seven subjects were tested exclusively with the pressure transducer puff monitoring system.

Immediately prior to and following each session, an approximately 1-liter sample of alveolar air was collected as described elsewhere (Henningfield, Stitzer, \& Griffiths, in press) and tested for $\mathrm{CO}$ content, using a breath-analyzing machine (Ecolyzer ${ }^{\circledR}$, Elmsford, New York). Other dependent variables included (1) latency to the first puff from session onset, (2) number of cigarettes smoked, (3) number of puffs, (4) duration of each cigarette, timed from the first puff to the last puff on the ciga- 
Table 2

Experiment 1: Mean and Coefficient of Variance (CV) of Dependent Variables During Ad-Lib Smoking

\begin{tabular}{|c|c|c|c|c|c|c|c|c|c|c|c|c|c|c|c|c|c|c|}
\hline \multirow{3}{*}{$\begin{array}{l}\text { Sub- } \\
\text { ject }\end{array}$} & \multirow{2}{*}{\multicolumn{2}{|c|}{$\underline{\text { Sessions }}$}} & \multirow{3}{*}{$\begin{array}{c}\text { Puffs per } \\
\text { Hour }\end{array}$} & \multirow{2}{*}{\multicolumn{2}{|c|}{$\begin{array}{l}\text { Cigarettes } \\
\text { per Hour }\end{array}$}} & \multirow{2}{*}{\multicolumn{2}{|c|}{$\begin{array}{l}\text { Puffs per } \\
\text { Cigarette }\end{array}$}} & \multirow{2}{*}{\multicolumn{2}{|c|}{$\begin{array}{l}\text { Seconds per } \\
\text { Cigarette }\end{array}$}} & \multirow{2}{*}{\multicolumn{2}{|c|}{$\begin{array}{l}\text { Seconds per } \\
\text { Puff }\end{array}$}} & \multicolumn{5}{|c|}{ CO Level (Parts/Million) } & \multirow{2}{*}{\multicolumn{2}{|c|}{$\begin{array}{c}\text { Butt } \\
\text { Weight }(\mathrm{g})\end{array}$}} \\
\hline & & & & & & & & & & & & \multicolumn{2}{|c|}{ Presession } & \multicolumn{2}{|c|}{ Postsession } & \multirow[b]{2}{*}{ Change } & & \\
\hline & $\mathrm{N}$ & & & Mean & $\mathrm{CV}$ & lean & $\mathrm{CV}$ & Mean & $\mathrm{CV}$ & Mean & $\mathrm{CV}$ & Mean & $\mathrm{CV}$ & Mean & $\mathrm{CV}$ & & Mean & $\mathrm{CV}$ \\
\hline A.M. & 7 & 1.5 & 5.98 & 4 & .0 & & .2 & & .1 & 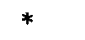 & & & & & .4 & +1.6 & 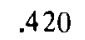 & .10 \\
\hline .0 & 5 & 3.0 & & & .14 & 1. & .17 & & .04 & .9 & .20 & & & & & & & .15 \\
\hline O.W. & 9 & 3.0 & & 1.94 & .19 & 4.7 & .13 & 464 & .08 & 1.3 & .06 & 22.2 & & & & 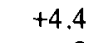 & & .09 \\
\hline H.E. & 8 & 3.0 & 10.46 & 1. & .23 & 6. & .16 & 416 & .14 & $*$ & & 1 & .1 & 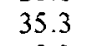 & .13 & +.2 & 6 & .04 \\
\hline G.A. & 10 & 1.5 & 1 & 2. & .16 & 4. & .21 & 447 & .27 & .68 & .10 & & .5 & & .12 & -3 & & .28 \\
\hline H.I. & 9 & 3.0 & 12.20 & 2.35 & .14 & 6.7 & .01 & 472 & .07 & 1.52 & .16 & & .2 & & .15 & +7 & .3 & .11 \\
\hline Y.A. & 5 & 3.0 & & 2.40 & .11 & 5.5 & .12 & 536 & .12 & $*$ & & & .2 & & .19 & & & .08 \\
\hline M.O. & 20 & 3.0 & & & .10 & 9.6 & .11 & 5 & .10 & $*$ & & & & & .2 & & & .09 \\
\hline H.A & 10 & 3.0 & & & .14 & 7 & .29 & & .13 & $*$ & & & .2 & & .32 & & & .17 \\
\hline T.A. & 10 & 1.5 & 1 & & .19 & 8 & .1 & 4 & .11 & .89 & .24 & 24.9 & & 29.2 & .18 & +4.3 & .368 & .14 \\
\hline D.A. & 5 & 3.0 & & 2 & .07 & 7 & .08 & & .07 & $*$ & & & & & & & & \\
\hline A.Y. & 10 & 3.0 & 90 & 1.73 & .22 & 11.5 & .10 & 448 & .17 & .93 & .43 & 26 & .38 & & .2 & & 0 & .13 \\
\hline M.C. & 10 & 3.0 & 20.71 & 1.57 & .17 & 13.2 & .18 & 350 & .11 & .76 & .19 & & .2 & 22.5 & .28 & +5 & & .11 \\
\hline S.T. & 10 & 1.5 & 20.96 & 2.67 & .11 & 7.9 & .15 & 334 & .11 & .79 & .24 & 19.5 & .14 & 21.4 & .10 & +1.9 & .510 & .13 \\
\hline P.I. & 5 & 3.0 & ( 1 & 173 & .14 & 12.3 & .20 & & & 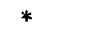 & & 16 & .1 & 15.1 & .31 & -.9 & & \\
\hline L.A & 20 & 3.0 & 2 & 2.80 & .10 & 7.7 & .11 & 437 & .08 & * & & 20.2 & .22 & 33.0 & .26 & +9.8 & .393 & .15 \\
\hline W.E. & 7 & 2.0 & & 3.52 & .13 & 7.6 & .17 & 411 & .19 & $*$ & & 31.3 & .18 & 39.9 & .12 & +8.6 & .443 & .10 \\
\hline W.A. & 10 & 1.5 & 38.47 & 3.13 & .19 & 12.3 & .14 & 209 & .17 & 1.23 & .17 & 15.4 & .17 & 18.1 & .12 & +2.7 & .353 & .05 \\
\hline M.I. & 10 & 1.5 & 77.20 & 5.13 & 19 & 15.1 & .13 & 316 & .15 & .99 & .16 & 30.6 & .17 & 37.0 & .09 & +6.4 & .409 & .05 \\
\hline Mean & & & 20.42 & 2.32 & & 8.5 & & 409 & & .99 & & 22.1 & & 26.3 & & +4.0 & .397 & \\
\hline
\end{tabular}

Note-Coefficient of variance $=S D /$ mean. Session durations are given in hours. Puffs per hour were calculated as cigarettes per hour times puffs per cigarette. Blank entries indicate data were not collected. *Data from these subjects were collected using the thermistor puff monitoring system, which did not permit measurement of puff duration.

rette, (5) duration of each puff (measured on the pressure transducer system), (6) number of puffs per cigarette, (7) the time during the session that each event occurred, (8) mean weight of the unsmoked portions of cigarette (butts), and (9) subjective ratings of general smoking satisfaction and other subjective factors of interest. A variety of additional measures can be derived from these variables, including rate of puffing per cigarette and percent of time spent smoking.

\section{Results}

Figure 2 (upper portion) shows patterns of smoking cigarettes for seven representative subjects during 3-h sessions. In addition, for each of these subjects, the pattern of puffing is shown for one representative cigarette. Within subjects, regular day-to-day patterns of smoking emerged within the first three sessions and usually remained stable through several weeks of study. Across subjects, Figure 1 shows that cigarettes were spaced regularly throughout the sessions, but patterns of puffing within cigarettes were more variable. For instance, subject Y.A. spaced puffs irregularly over each cigarette, whereas M.C. puffed in a very regular temporal pattern. Within cigarettes, puffing frequently occurred in a negatively accelerated pattern and rarely in a positively accelerated pattern. However, as shown in Figure 1, this rule was not invariant. Table 2 presents a summary of results from some of the more interesting smoking measures. Cigarettes were smoked at an average rate of 2.32 cigarettes/ $h$, which roughly corresponds to selfreports of daily rates of smoking outside the research setting (Table 1). Puffs per cigarette averaged 8.5 , with a range of 4.3-15.1. Puffs per hour reflected both puffs per cigarette and cigarettes per hour and also varied considerably across subjects. Average cigarette duration, as measured from the first puff to the last puff, was $6.8 \mathrm{~min}$. Expired air CO levels usually increased over the sessions, and the amount of increase was roughly correlated with rate of puffing per hour and number of cigarettes smoked per hour (Table 2). No meaningful relationships

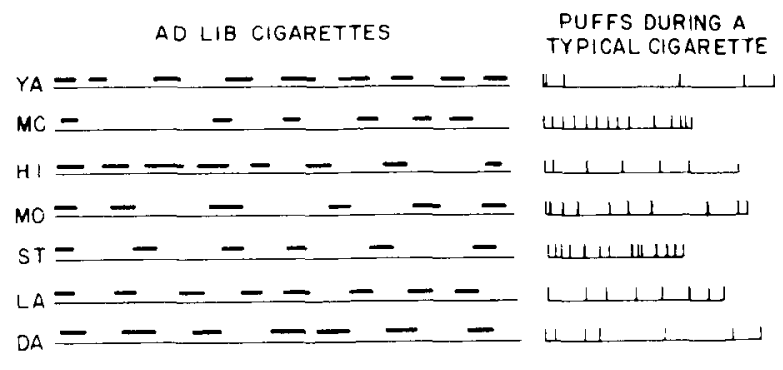

RESTRICTED NUMBER OF CIGARETTES

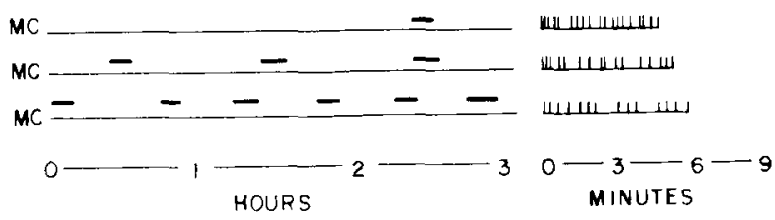

Figure 2. For each of seven subjects, cigarettes during a typical session are indicated by horizontal bars on the left side of the figure, and puffs during a representative cigarette of the same session are indicated by vertical lines on the right side of the figure. The upper seven records show data obtained under the ad-lib smoking conditions of Experiment 1. The lower three records show data obtained when cigarette intake was restricted to one, three, or six cigarettes per session during Experiment 2. 
were apparent between variables such as subject's age, sex, years of smoking, history of substance abuse, or brand of cigarettes smoked, although self-report of daily rate of smoking was a reasonably good predictor of session cigarette smoking rate. Session duration did not appear to systematically affect measures of smoking. Puff duration averaged $.99 \mathrm{sec} /$ puff across 10 subjects. Subjects usually puffed on their first cigarette within the first few minutes of sessions, probably reflecting the 30-min minimum deprivation period. Cigarette butt weight varied considerably across subjects but varied little within subjects. Coefficient of covariance scores, rather than standard error values, are shown in Table 1 , thus providing a basis to evaluate the relative variability of data generated by the various measures of smoking. For example, within subjects, variability about the mean was lowest with seconds per cigarette, cigarettes per hour, puffs per cigarette, and mean cigarette butt weight; variability about the mean was greater for the seconds-per-puff measure and greatest for measures of $\mathrm{CO}$ level. Intermittent visual monitoring of sessions suggested that the two types of puff monitoring systems were equally reliable and valid. Finally, observational data plus self-reports from subjects indicated that these experimental conditions permit subjects to smoke spontaneously and in a relatively natural manner as they watch television or read the newspaper.

\section{EXPERIMENT 2: EFFECTS OF VARYING THE NUMBER OF CIGARETTES AVAILABLE DURING 3-H SESSIONS}

Following observations of regular spacing of cigarettes during unrestricted access in Experiment 1, we were interested in possible changes in patterning produced by varying the number of cigarettes that were available. This manipulation was also of interest in light of clinical reports that smokers who decrease their daily cigarette intake tend to compensate by altering their topography and pattern of smoking.

\section{Method}

Subjects and Apparatus. Three subjects who had served in Experiment 1 participated in this study (M.C., A.Y., and R.O.). The test room and equipment were the same as those described in Experiment 1; however, only Chamber 1, equipped with the pressure transducer system, was used in this experiment, so that puff duration could be measured.

Procedure. The general procedure was the same as that described in Experiment 1, with one main exception: Prior to the start of the session, the experimenter collected all cigarettes from the subject and then gave the subject a cup containing one, three, or six cigarettes or a full pack (ad-lib condition). During the one-, three-, and six-cigarette conditions, subjects were instructed to smoke all of the cigarettes, but to smoke as they pleased, using the smoking apparatus. During the ad-lib condition, subjects were free to smoke as many cigarettes as they desired. These four smoking conditions were presented in a randomized block order across sessions; each condition was presented once during each of the four randomly determined sequences, except for subject R.O., who was exposed to each condition only twice. Immediately following sessions, the subjects rated cigarette craving on a 5-point scale (very strong to very weak) and general smoking satisfaction on a 5-point scale (much less satisfying than usual to much more satisfying than usual).

\section{Results}

The most striking finding of this study was that regular spacing of cigarette smoking occurred under all smoking conditions. This result is shown for subject M.C. in Figure 2 (lower portion). One measure of this effect was latency to the first puff of the session, which was inversely related to the number of cigarettes smoked. One subject who did not complete this study (H.I. from Experiment 1) sequentially lit, puffed, and extinguished each cigarette during the three-cigarette condition four times, resulting in 12 equally spaced bouts of smoking throughout the session. Thus, the regular spacing of cigarettes observed in Experiment 1 persisted when number of cigarettes was restricted and perhaps was even more regular in Experiment 2.

Decreasing the number of cigarettes that subjects were permitted to smoke resulted in somewhat increased numbers of puffs per cigarette. Table 3 shows that changes in expired air $\mathrm{CO}$ level were directly related to

Table 3

Experiment 2: Means and Standard Errors of the Mean (SEM) of Dependent Variables as a Function of Number of Cigarettes Smoked

\begin{tabular}{|c|c|c|c|c|c|c|c|c|c|c|c|c|c|c|c|c|c|c|}
\hline \multirow{3}{*}{$\begin{array}{l}\text { Sub- } \\
\text { ject }\end{array}$} & \multirow{3}{*}{$\begin{array}{c}\text { Condi } \\
\text { tion }\end{array}$} & \multirow{2}{*}{\multicolumn{2}{|c|}{$\begin{array}{c}\text { Cigarettes } \\
\text { Smoked } \\
\end{array}$}} & \multirow{2}{*}{\multicolumn{2}{|c|}{$\begin{array}{c}\text { Seconds to } \\
\text { First Puff }\end{array}$}} & \multirow{2}{*}{\multicolumn{2}{|c|}{$\begin{array}{l}\text { Puffs per } \\
\text { Cigarette }\end{array}$}} & \multirow{2}{*}{\multicolumn{2}{|c|}{$\begin{array}{c}\text { Seconds per } \\
\text { Cigarette }\end{array}$}} & \multirow{2}{*}{\multicolumn{2}{|c|}{$\begin{array}{l}\text { Seconds } \\
\text { per Puff }\end{array}$}} & \multicolumn{5}{|c|}{ CO Level (Parts/Million) } & \multirow{2}{*}{\multicolumn{2}{|c|}{$\begin{array}{c}\text { Butt } \\
\text { Weight (g) } \\
\end{array}$}} \\
\hline & & & & & & & & & & & & \multicolumn{2}{|c|}{ Presession } & \multicolumn{2}{|c|}{ Postsession } & \multirow[b]{2}{*}{ Change } & & \\
\hline & & Mean & SEM & Mean & SEM & Mean & SEM & Mean & SEM & Mean & SEM & Mean & SEM & Mean & SEM & & Mean & SEM \\
\hline M.C. & $\begin{array}{l}1 \\
3 \\
6 \\
\text { F }\end{array}$ & $\begin{array}{l}1.0 \\
3.0 \\
6.0 \\
6.0\end{array}$ & $\begin{array}{l}.00 \\
.00 \\
.00 \\
.40\end{array}$ & $\begin{array}{r}7,676 \\
2,442 \\
214 \\
373\end{array}$ & $\begin{array}{r}345 \\
415 \\
70 \\
145\end{array}$ & $\begin{array}{l}18.0 \\
17.5 \\
15.0 \\
15.2\end{array}$ & $\begin{array}{l}.5 \\
.8 \\
.9 \\
.4\end{array}$ & $\begin{array}{l}308 \\
359 \\
308 \\
348\end{array}$ & $\begin{array}{l}11 \\
12 \\
15 \\
10\end{array}$ & $\begin{array}{l}.65 \\
.78 \\
.79 \\
.89\end{array}$ & $\begin{array}{l}.40 \\
.40 \\
.02 \\
.02\end{array}$ & $\begin{array}{l}18.3 \\
19.3 \\
19.0 \\
18.7\end{array}$ & $\begin{array}{r}1.8 \\
.6 \\
3.0 \\
1.5\end{array}$ & $\begin{array}{l}16.8 \\
17.3 \\
18.5 \\
19.7\end{array}$ & $\begin{array}{l}7.3 \\
2.6 \\
4.0 \\
1.9\end{array}$ & $\begin{array}{r}-1.5 \\
-2.0 \\
-\quad .5 \\
+1.2\end{array}$ & $\begin{array}{l}.353 \\
.338 \\
.354 \\
.331\end{array}$ & $\begin{array}{l}.025 \\
.035 \\
.013 \\
.009\end{array}$ \\
\hline A.Y. & $\begin{array}{l}1 \\
3 \\
6 \\
F\end{array}$ & $\begin{array}{l}1.0 \\
3.0 \\
6.0 \\
5.8\end{array}$ & $\begin{array}{l}.00 \\
.00 \\
.00 \\
.41\end{array}$ & $\begin{array}{r}6,315 \\
689 \\
155 \\
243\end{array}$ & $\begin{array}{r}418 \\
107 \\
37 \\
94\end{array}$ & $\begin{array}{l}14.5 \\
15.1 \\
12.5 \\
11.1\end{array}$ & $\begin{array}{l}.6 \\
.9 \\
.4 \\
.7\end{array}$ & $\begin{array}{l}456 \\
493 \\
468 \\
324\end{array}$ & $\begin{array}{l}21 \\
18 \\
16 \\
37\end{array}$ & $\begin{array}{r}.77 \\
1.04 \\
.75 \\
1.14\end{array}$ & $\begin{array}{l}.11 \\
.20 \\
.08 \\
.58\end{array}$ & $\begin{array}{l}25.3 \\
27.4 \\
24.8 \\
24.2\end{array}$ & $\begin{array}{r}.5 \\
3.4 \\
2.3 \\
7.7\end{array}$ & $\begin{array}{l}19.1 \\
27.1 \\
34.7 \\
37.0\end{array}$ & $\begin{array}{r}1.5 \\
.5 \\
1.3 \\
4.4\end{array}$ & $\begin{array}{r}-6.2 \\
-\quad .3 \\
+9.9 \\
+12.8\end{array}$ & $\begin{array}{l}.468 \\
.420 \\
.492 \\
.497\end{array}$ & $\begin{array}{l}.020 \\
.044 \\
.925 \\
.013\end{array}$ \\
\hline R.O. & $\begin{array}{l}1 \\
3 \\
6 \\
\mathrm{~F}\end{array}$ & $\begin{array}{l}1.0 \\
3.0 \\
6.0 \\
3.0 \\
\end{array}$ & $\begin{array}{l}.00 \\
.00 \\
.00 \\
.00 \\
\end{array}$ & $\begin{array}{r}4,579 \\
583 \\
258 \\
165 \\
\end{array}$ & $\begin{array}{r}945 \\
230 \\
162 \\
39 \\
\end{array}$ & $\begin{array}{r}12.0 \\
7.2 \\
4.4 \\
7.5 \\
\end{array}$ & $\begin{array}{r}5.0 \\
.9 \\
.4 \\
1.5 \\
\end{array}$ & $\begin{array}{l}274 \\
408 \\
282 \\
400 \\
\end{array}$ & $\begin{array}{r}88 \\
4 \\
90 \\
16 \\
\end{array}$ & $\begin{array}{l}.74 \\
.59 \\
.93 \\
.76 \\
\end{array}$ & $\begin{array}{l}.23 \\
.08 \\
.05 \\
.12 \\
\end{array}$ & $\begin{array}{r}8.0 \\
8.0 \\
9.8 \\
18.0 \\
\end{array}$ & & $\begin{array}{r}8.0 \\
9.0 \\
12.3 \\
14.5\end{array}$ & & $\begin{array}{r}.0 \\
+\quad 1.0 \\
+\quad 2.5 \\
-3.5 \\
\end{array}$ & $\begin{array}{l}.345 \\
.357 \\
.296 \\
.335\end{array}$ & $\begin{array}{l}.011 \\
.030 \\
.004 \\
.013\end{array}$ \\
\hline
\end{tabular}

Note-Data for subject R.O. are means of two observations at each condition except CO determinations, in which $n=1$. 
number of cigarettes smoked. Subjective ratings of smoking satisfaction and craving were variable and not systematically related to number of cigarettes smoked. When changes in puff duration or cigarette duration occurred, both were typically in the direction of shorter durations at one cigarette. These changes may reflect attempts to increase the efficiency of extraction of tobacco products from the cigarettes.

\section{EXPERIMENT 3: CIGARETTE SMOKING AS A FUNCTION OF CIGARETTE DEPRIVATION}

Experiments 1 and 2 showed that orderly patterns of cigarette smoking were obtained in the experimental preparation and that regularity of smoking behavior was maintained when cigarette availability was restricted. To better assess the validity of this preparation, we next manipulated cigarette deprivation state, since this is a manipulation whose outcome was suspected on an a priori basis. Specifically, naturalistic observations and clinical reports of smokers suggest that cigarette deprivation should increase the tendency to smoke. Tendency to smoke in this experiment was defined as the latency to the first puff from the onset of the session.

\section{Method}

Three individuals who had served in Experiment 1 (H.I. M.C., S.T.) were subjects. Experimental sessions were $3 \mathrm{~h}$, and subjects were free to smoke as they chose while following the general protocol described for Experiment 1. For an additional $3 \mathrm{~h}$ preceding each daily session, subjects were retained in a waiting room near the smoking chamber and smoked cigarettes under one of the following three schedules: one cigarette every $30 \mathrm{~min}$, finishing the last cigarette $2 \mathrm{~min}$ before the start of a test session (0-h deprivation); one cigarette every $30 \mathrm{~min}$, finishing the last cigarette $1 \mathrm{~h}$ before the start of a test session (1-h deprivation); no cigarettes smoked during the 3-h presession period (3-h deprivation). The pressure transducer puff monitoring system was used so that puff duration could be measured. Other measures of smoking were the same as described previously.

\section{Results}

Latency to the first puff in a test session (Figure 3) was a direct function of deprivation period: As hours of deprivation increased, latency decreased. Number of cigarettes smoked and total number of puffs per session were less sensitive indicators of smoking deprivation; when these variables did change, it was in the direction of increasing smoking rates along with increasing deprivation (Table 4). Puff duration did not vary systemati-

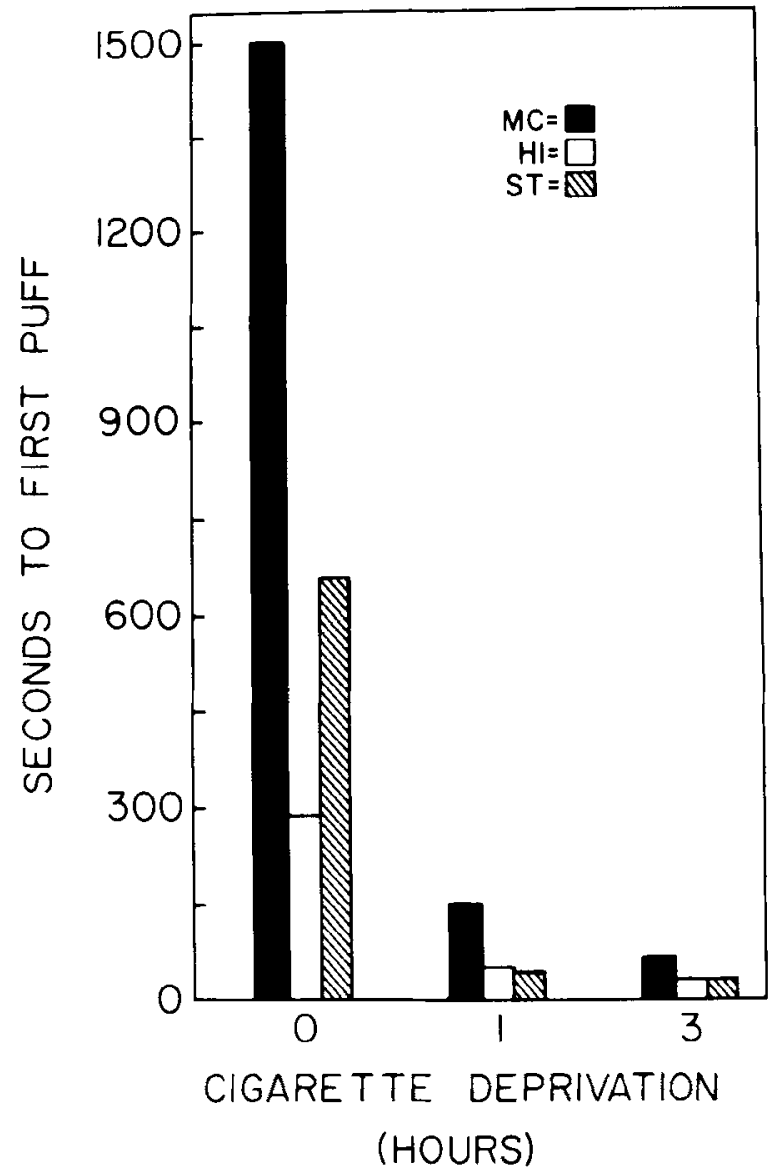

Figure 3. For each subject in Experiment 3, the mean number of seconds from the start of the session until the first puff occurred are shown as a function of hours of deprivation of cigarette smoking. Standard error values may be seen in Table 4.

Table 4

Experiment 3: Means and Standard Errors of the Mean of Dependent Variables as a Function of Deprivation

\begin{tabular}{|c|c|c|c|c|c|c|c|c|c|c|c|c|c|c|c|c|c|}
\hline \multirow{3}{*}{$\begin{array}{l}\text { Sub- } \\
\text { ject }\end{array}$} & \multirow[b]{3}{*}{$D^{*}$} & \multirow{2}{*}{\multicolumn{2}{|c|}{$\begin{array}{l}\text { Seconds to } \\
\text { First Puff }\end{array}$}} & \multirow{2}{*}{\multicolumn{2}{|c|}{$\begin{array}{l}\text { Cigarettes } \\
\text { Smoked }\end{array}$}} & \multirow{2}{*}{\multicolumn{2}{|c|}{ Puffs }} & \multirow{2}{*}{\multicolumn{2}{|c|}{$\begin{array}{l}\text { Seconds per } \\
\text { Cigarette }\end{array}$}} & \multirow{2}{*}{\multicolumn{2}{|c|}{$\begin{array}{l}\text { Seconds per } \\
\text { Puff }\end{array}$}} & \multicolumn{4}{|c|}{ CO Level (Parts/Million) } & \multirow{2}{*}{\multicolumn{2}{|c|}{$\begin{array}{c}\text { Butt } \\
\text { Weight (g) }\end{array}$}} \\
\hline & & & & & & & & & & & & Preses & ion & Posts & ion & & \\
\hline & & Mean & SEM & Mean & SEM & Mean & SEM & Mean & SEM & Mean & SEM & Mean & SEM & Mean & SEM & Mean & SEM \\
\hline M.C. & $\begin{array}{l}0 \\
1 \\
3\end{array}$ & $\begin{array}{r}1,497 \\
146 \\
63\end{array}$ & $\begin{array}{r}450 \\
56 \\
11\end{array}$ & $\begin{array}{l}5.0 \\
5.3 \\
5.7\end{array}$ & $\begin{array}{l}.0 \\
.3 \\
.3\end{array}$ & $\begin{array}{l}77.0 \\
80.0 \\
86.3\end{array}$ & $\begin{array}{r}6.7 \\
8.5 \\
12.7\end{array}$ & $\begin{array}{l}371 \\
367 \\
344\end{array}$ & $\begin{array}{r}14 \\
11 \\
4\end{array}$ & $\begin{array}{l}.82 \\
.90 \\
.80\end{array}$ & $\begin{array}{l}.09 \\
.03 \\
.07\end{array}$ & & $\begin{array}{l}6.4 \\
3.2 \\
2.3\end{array}$ & $\begin{array}{l}25.3 \\
25.3 \\
20.7\end{array}$ & $\begin{array}{l}2.3 \\
1.6 \\
3.1\end{array}$ & $\begin{array}{l}.345 \\
.345 \\
.335\end{array}$ & $\begin{array}{l}.023 \\
.018 \\
.009\end{array}$ \\
\hline H.I & $\begin{array}{l}0 \\
1 \\
3\end{array}$ & $\begin{array}{r}275 \\
54 \\
32\end{array}$ & $\begin{array}{r}96 \\
5 \\
2\end{array}$ & $\begin{array}{l}7.0 \\
7.3 \\
7.0\end{array}$ & $\begin{array}{r}.0 \\
1.2 \\
.0\end{array}$ & $\begin{array}{l}48.7 \\
48.3 \\
45.7\end{array}$ & $\begin{array}{l}1.2 \\
7.3 \\
1.9\end{array}$ & $\begin{array}{l}461 \\
455 \\
500\end{array}$ & $\begin{array}{l}17 \\
21 \\
25\end{array}$ & $\begin{array}{l}1.54 \\
1.52 \\
1.54\end{array}$ & $\begin{array}{l}.19 \\
.21 \\
.04\end{array}$ & $\begin{array}{l}44.5 \\
30.5 \\
31.0\end{array}$ & $\begin{array}{r}.4 \\
.7 \\
7.6\end{array}$ & $\begin{array}{l}44.5 \\
39.7 \\
43.0\end{array}$ & $\begin{array}{l}2.0 \\
2.0 \\
3.8\end{array}$ & $\begin{array}{l}.378 \\
.357 \\
.368\end{array}$ & $\begin{array}{l}.015 \\
.005 \\
.018\end{array}$ \\
\hline S.T. & $\begin{array}{l}0 \\
1 \\
3\end{array}$ & $\begin{array}{r}663 \\
44 \\
35\end{array}$ & $\begin{array}{r}17.8 \\
5 \\
2\end{array}$ & $\begin{array}{l}5.3 \\
6.0 \\
7.7\end{array}$ & $\begin{array}{l}.3 \\
.6 \\
.3\end{array}$ & $\begin{array}{l}51.0 \\
68.0 \\
82.3\end{array}$ & $\begin{array}{l}7.0 \\
6.7 \\
8.1\end{array}$ & $\begin{array}{l}312 \\
287 \\
293\end{array}$ & $\begin{array}{r}13 \\
18 \\
9\end{array}$ & $\begin{array}{l}.65 \\
.83 \\
.84\end{array}$ & $\begin{array}{l}.12 \\
.01 \\
.03\end{array}$ & $\begin{array}{l}23.8 \\
21.3 \\
16.3\end{array}$ & $\begin{array}{l}3.1 \\
2.6 \\
2.3\end{array}$ & $\begin{array}{l}23.5 \\
23.5 \\
22.7\end{array}$ & $\begin{array}{l}2.5 \\
5.8 \\
5.9\end{array}$ & $\begin{array}{l}.431 \\
.413 \\
.431\end{array}$ & $\begin{array}{l}.016 \\
.036 \\
.020\end{array}$ \\
\hline
\end{tabular}

*Deprivation in hours. 
cally. Patterning of smoking cigarettes was similar to that shown in Figure 1, and the only observable change across smoking conditions was an increasing tendency toward negative acceleration of session smoking as deprivation increased. This resulted from increases in number of cigarettes smoked during the first hour and not to increases in puffs per cigarette on earlier session cigarettes. Presession $\mathrm{CO}$ levels were inversely related to hours of deprivation, although postsession $\mathrm{CO}$ levels were generally similar across conditions. The presession deprivation-induced decreases in $\mathrm{CO}$ level confirm the sensitivity of expired air $\mathrm{CO}$ as a measure of prior smoking activity.

\section{DISCUSSION}

The preparation for the experimental analysis of human cigarette smoking noted here consists of a comfortable, naturalistic, experimental environment equipped with a cigarette smoking monitoring system that permits the collection of a wide range of potentially useful dependent variables. Observational data and subjective reports from 19 subjects indicate that cigarette smoking in this environment occurs spontaneously and is relatively unconstrained by the apparatus. Experiment 1 was a descriptive study of temporal and topographical aspects of the cigarette smoking occurring in this environment. Nineteen heavy and inhaling smokers developed patterns of regular temporal spacing of cigarettes with variations in absolute rate ranging roughly from 1 to 5 cigarettes/h. Temporal spacing of puffing was variable across subjects, and rates ranged from approximately 6 to $80 \mathrm{puffs} / \mathrm{h}$. Within individuals, patterns of smoking cigarettes and of puffing within cigarettes were similar across sessions, and the relatively low coefficient of covariance values confirm the high degree of stereotypy in the behavior of smoking. Experiments 2 and 3 were undertaken to assess the sensitivity and reliability of the dependent variables and to determine the validity of the preparation as an experimental model for cigarette smoking in the nonlaboratory environment. In Experiment 2 it was shown that restricting the number of cigarettes available increased rates of puffing during smoking but that regular spacing of the cigarettes was maintained. Experiment 3 showed that tendency to smoke could be quantified and was a direct function of hours of cigarette deprivation. Topographical aspects of smoking were relatively unaffected by changes in deprivation level, and this study confirmed that the $\mathrm{CO}$ measure is a reliable although imprecise indicator of prior smoking activity.

The findings generated by this experimental preparation are orderly and are consistent with one of the most widely confirmed generalities from earlier studies of smoking; that is, when the amount of smoke available to a smoker is experimentally manipulated, smokers tend to engage in compensatory changes to defend their usual smoking level. Specifically, studies show that compensatory changes in smoking occur when the amount of smoke is manipulated by diluting the concentration of smoke with cigarette holders (Sutton, Feyerabend, Cole, \& Russell, 1978; Henningfield \& Griffiths, Note 1) and by cutting cigarettes into smaller portions (Gritz, Baer-Weiss, \& Jarvik, 1976, Jarvik, Popek, Schneider, Baer-Weiss, \& Gritz, 1978). Related studies show that preloading a smoker with cigarette smoke increases the latency to the first puff (Kozlowski, Jarvik, \& Gritz, 1975; Kumar, Cooke, Lader, \& Russell, 1977).

Counting as puffs only those measured at intervals of greater than $5 \mathrm{sec}$ eliminated several potential artifacts. For instance, the operation of lighting a cigarette produced multiple operations of either the pressure transducer or the thermistor system, but usually only one actual inhalation of tobacco product was observed. At other times, the sensitivity of the puff monitors occasionally permitted multiple operations of the equipment, while visual observations indicated that only one functional puff had occurred and this was followed by one discrete inhalation of tobacco product. At no time did visual observations indicate that more than one sequence of puffing and inhaling occurred within the 5 -sec minimum interpuff interval. Thus, the 5 -sec value seemed short enough to reliably detect legitimate puffs, but long enough that the number of puffs counted closely reflected the number of smoke inhalations and that lighting cigarettes did not produce artifactual puff counts.

There are several reasons that an experimental preparation, such as the one described in this report, can serve in the analysis of cigarette smoking behavior and its controlling variables. At a general level, relatively little is known about the temporal and topographical aspects of cigarette smoking behavior. This is important in the understanding of any form of substance selfadministration, and it is particularly important in cigarette smoking since these parameters (e.g., puff rate) can greatly affect the quantity of tobacco product intake and determine whether tobacco products such as nicotine and $\mathrm{CO}$ produce blood-level peaks or gradual changes in blood level (Russell \& Feyeraband, 1978). More specifically, it is important to measure a wide range of variables since it is probable that there is a differential sensitivity of dependent variables to experimental manipulations. For example, the most commonly used measure in cigarette smoking research, self-report of number of cigarettes smoked per day, is notoriously insensitive and may be confounded by bias and misrepresentation (Ohlin, Lundh, \& Westling, 1976); there is a variety of superior and objective measures potentially available (Russell, 1976). Furthermore, choice of only one or two objective measures may still fail to detect important changes in behavior; for example, cigarette intake and puffing can both vary independently of actual intake of the tobacco products (Russell, 1976). The more interesting and useful variables in the current study are temporal aspects of smoking cigarettes, puffing within cigarettes, latency to the first puff of a session, and expired air CO level. Taken together, 
these variables constitute a quantitative description of cigarette smoking behavior.

The reliability and validity of this preparation and its measures can be evaluated in several ways. Initially, daily sessions were visually monitored to assure that data collected by the computer corresponded to the behavior of the subject. This assured, reliability has been assessed at a behavioral level in terms of regularity of the measures across cigarettes and across sessions, and while the sensitivity of the dependent variables varies, measures are generally consistent with each other. Finally, the results of the three experiments are generally consistent with a priori predictions resulting from naturalistic observations of cigarette smokers as well as the available literature.

The present research preparation is one stage of development in a cigarette smoking research methodology that has been rapidly evolving in recent years. Progress in both the conceptual framework from which cigarette smoking is considered and the technology used to study the behavior have been equally important. The conceptual framework has evolved from the perspective that smoking is essentially an instance of psychological dependence or a powerful habit, albeit a persistent one, to the notion that cigarette smoking may be regarded as a legitimate form of drug dependence or substance abuse (Gritz \& Jarvik, 1978; Jaffe \& Kanzler, 1979; Russell \& Feyerabend, 1978). Such a conceptual advance renders cigarette smoking amenable to the research strategies of behavioral pharmacology and the experimental analysis of substance abuse. Technologically, advances have been made in the development and application of instruments to measure intake of the products of burning tobacco (Frederiksen \& Martin, 1979; Russell, 1976), in the measurement of topographical aspects of smoking (e.g., Jarvik et al., 1978), and in the analysis of the constituents of tobacco products along with the attendant development of experimental cigarettes that permit selective variation of the components. Together, these developments should facilitate more rapid advances in research and should permit studies to be done that are less susceptible to criticism and divergent interpretations.

\section{REFERENCE NOTE}

1. Henningfield, J. E., \& Griffiths, R. R. Effects of ventilated cigarette holders on cigarette smoking by humans. Manuscript submitted for publication.

\section{REFERENCES}

Frederiksen, L. W., \& Martin, J. E. Carbon monoxide and smoking behavior. Addictive Behaviors, 1979, 4, 21-30.

Gritz, E. R., BaEr-Weiss, V., \& JarviK, M. E. Titration of nicotine intake with full-length and half-length cigarettes. Clinical Pharmacology and Therapeutics, 1976, 20, 552-556.

Gritz, E. R., \& Jarvik, M. E. Nicotine and smoking. In L. L. Iverson, S. D. Iverson, \& S. H. Snyder (Eds.), Handbook of psychopharmacology (Vol. 2). New York: Plenum, 1978.

Henningfield, J. E., Stitzer, M. L., \& Griffiths, R. R. Patterns of carbon monoxide accumulation and elimination as a function of number of cigarettes smoked. Addictive Behaviors, in press.

Honn, D. A model for the study of personal choice health behavior. International Journal of Health Education, 1976, 19, 89-88.

JAFFE, J. H., \& KAnzLER, M. Smoking as an addictive disorder. In Cigarette smoking as a dependence process (NIDA Research Monograph No. 23). Washington, D.C: U.S. Government Printing Office, 1979.

JARVIK, M. E. The role of nicotine in the smoking habit. In W. A. Hunt (Ed.), Learning mechanisms in smoking behavior. Chicago: Aldine, 1970.

Jarvik, M. E., Popek, P., Schneider, N. G., Baer-Weiss, V., \& GRITz, E. Can cigarette size and nicotine content influence smoking and puffing rates? Psychopharmacology, 1978, 58, 303-306.

Kozlowski, L. T., Jarvik, M. E., \& Gritz, E. R. Nicotine regulation and cigarette smoking. Clinical Pharmacology and Therapeutics, 1975, 17, 93-97.

Kumar, R., Cooke, E. C., Lader, M. H., \& Russell, M. A. H. Is nicotine important in tobacco smoking? Clinical Pharmacology and Therapeutics, 1977, 21, 520-529.

Ohlin, P., Lundh, B., \& Westling, H. Carbon monoxide blood levels and reported cessation of smoking. Psychopharmacology, 1976, 49, 263-265.

Russell, M. A. H. Tobacco smoking and nicotine dependence. In R. J. Gibbins, Y. Israel, H. Kalant, R. E. Popham, W. Schmidt, \& R. G. Smart (Eds.), Research advances in and drug problems. New York: Wiley, 1976.

Russell, M. A. H. Tobacco dependence: Is nicotine rewarding or aversive? In Cigarette smoking as a dependence process (NIDA Research Monograph No. 23). Washington, D.C: U.S. Government Printing Office, 1979.

Russell, M. A. H., \& Feyerabend, C. Cigarette smoking: A dependence on high nicotine boli. Drug Metabolism Revues, $1978,8,29-57$.

SCHACTER, S. Regulation, withdrawal, and nicotine addiction. In Cigarette smoking as a dependence process (NIDA Research Monograph No. 23). Washington, D.C: U.S. Government Printing Office, 1979.

Sutton, S. R., Feyerabend, C., Cole, P. V., \& Russell, M. A. H. Adjustment of smokers to dilution of tobacco smoke by ventilated cigarette holders. Clinical Pharmacology and Therapeutics, 1978, 24, 395-405.

(Received for publication September 7, 1979; revision accepted October 29, 1979.) 